\title{
Australian Journal of \\ Crop Science \\ Evaluation of intra-cultivar variability in Olea europaea L. cv. Leccino using morphological, biochemical and molecular markers
}

\author{
Raffaella Petruccelli ${ }^{1 *}$, Deborah Beghè ${ }^{2}$, Tommaso Ganino ${ }^{2,1}$, Giorgio Bartolini ${ }^{1}$, Leonardo Ciaccheri ${ }^{3}$, \\ Rodolfo Bernardi ${ }^{4}$, Mauro Durante ${ }^{4}$
}

${ }^{1}$ Istituto per la Valorizzazione del Legno e delle Specie Arboree (IVALSA), Consiglio Nazionale delle Ricerche (CNR), Via Madonna del Piano, 10, 50019 Sesto Fiorentino, Italy

${ }^{2}$ Dipartimento di Scienze degli Alimenti e del Farmaco, Università degli Studi di Parma, Parco Area delle Scienze, 27/a, 43124 Parma, Italy

${ }^{3}$ Istituto di Fisica Applicata “Nello Carrara” (IFAC), Consiglio Nazionale delle Ricerche (CNR), Via Madonna del Piano, 10, 50019 Sesto Fiorentino, Italy

${ }^{4}$ Dipartimento di Scienze Agrarie, Alimentari e Agro-ambientali, Università degli Studi di Pisa Via del Borghetto, 80, 56124 Pisa, Italy

*Corresponding author: petruccelli@ivalsa.cnr.it

\section{Abstract}

The phenotypic and genotypic variability of olive tree Leccino cv (Olea europaea L.), an ancient cultivar from North-Central Italy, was investigated using 44 quantitative and qualitative agro-morphological traits, SDS-PAGE of seed proteins (storage proteins and tegument proteins) and molecular markers such as RAPDs (30 primers) and SSRs (8 primers). Fifteen accessions of Olea europaea catalogued as "Leccino" and one certified tree of "Leccino" (LESt) were examined. The plants were clonally propagated and the measuring of all morphological characteristics was conducted over a period of seven years. The ANOVA analysis showed that all accessions were homogenous for many traits while very few variations were recorded for length of one year old shoots, leaf width, leaf length/leaf width ratio, fruit length, fruit fresh weight, fruit length/fruit width ratio, pit length and pit fresh weight. The PCA analysis and similarity coefficients confirmed a low level of variability of Leccino cultivar. SDS-PAGE analysis of seed proteins showed monomorphic patterns of storage proteins. Protein subunits of teguments revealed a generally high level of similarity as evidenced by Nei-Li coefficient. SSRs and RAPDs markers showed molecular monomorphism among Leccino accessions. The results of agro-morphological, biochemical and molecular nature, taken as a whole, seem to indicate a weakly differentiated/homogeneity of the accessions tested belonging to the Leccino cultivar. The limited morphological and genetic variation could support the assumptions of a monophyletic origin of Leccino cultivar with a genetically restricted base.

Keywords: Olea europaea L., Leccino cultivar, intra-cultivar variability, morphological traits, molecular markers, seed proteins. Abbreviations: AT_Cross-sectional area of trunk $\left(\mathrm{cm}^{2}\right), \mathrm{CY}$ _Cumulate production $(\mathrm{Kg}), \mathrm{CYE}$ PProduction Efficiency $1\left(\mathrm{Kg} / \mathrm{cm}^{2}\right)$, CP_Canopy Projection to the soil $\left(\mathrm{m}^{2}\right), \mathrm{CTAB} \_$Cetyl trimethylammonium bromide, CV_coefficient variation, cv_cultivar, Frcol_Fruit color at mature stage, FrD_Max Fruit position of maximum diameter, Frepi_Fruit epicarp, FrFW_Fruit fresh weight (g), FrL_Fruit length $(\mathrm{cm}), \mathrm{FrL} / \mathrm{FrW}$ _Fruit length/width ratio, Frlen_Fruit lenticels, Fl/P_Flesh/pit weight ratio, FrW_width ratio (cm), Frsym_Fruit symmetry, Frnip_Fruit nipple, FrSH_Fruit shape, FrSHa_Fruit shape apex, FrSHb_Fruit shape base, FrY_Fruit yield per plant (Kg), ILSh_Intermodal length of one year old shoots $(\mathrm{cm})$, LA_Leaf area $\left(\mathrm{cm}^{2}\right)$, Laa_Leaf apex angle, Lba_Leaf base angle, Lcol_Leaf upper page colour, LESt_certified cultivar of Leccino, LFW_leaf fresh weight $(\mathrm{g})$, LL_Leaf length $(\mathrm{cm}), \mathrm{LW}_{-}$Leaf width (cm), LL/LW_Leaf length/width ratio, LSH_Leaf shape, LSh_Length of one-year-old shoots (cm), NG_Number of grooves (n), NNSh_node numbers (n), PFW_Pit fresh weight $(\mathrm{g})$, PH_Plant Height $(\mathrm{m})$, PL_Pit length $(\mathrm{cm})$, PL/PW_Pit length/width ratio, PMUC_Pit mucron, PSH_Pit Shape, PSHa_Pit shape apex, PSHb_Pit shape base, Psym_Pit symmetry, Psur_Pit surface, PVP_Polyvinylpyrrolidone, PW_Pit width

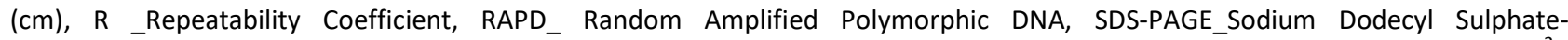
PolyAcrylamide Gel Electrophoresis, SSR_Simple Sequence Repeat, TYE_Production Efficiency2 (Kg/cm²).

\section{Introduction}

Olea europaea L. is a fruit species that has played an important socio-economic role for local communities and it is widely used in different industries from food to pharmacology, from medicine to cosmetics (Vossen, 2007). The genetic patrimony of olive is very rich indeed, and the number of olive varieties worldwide exceeds 1700 (Bartolini, 2008). Many of the cultivars are of unknown origin and it is not possible to define their progenitors or the "founder plant". Morphological, biochemical and molecular markers were elaborated in order to differentiate the olive cultivars, 
and to reveal homonyms, synonyms, or intra-cultivar variability (Ganino et al., 2006). The intra-cultivar variability, observed in the same olive cultivar, is attributed to somatic mutations occurring during vegetative propagation (Roselli et al., 1982; Lopes et al., 2004). The olive cultivars may consist of a single clone (monoclonal variety) or a number of very similar clones (polyclonal variety), where clone is meant as "an ensemble of genetically uniform individuals, derived originally from a single individual by asexual propagation, i.e., by cutting, division, grafting or obligate apomixis" (Ganino et al., 2006). The study of intra-varietal variability is important because the different clones may represent a potential source of genetic material useful for the transmission of specific production traits (e.g. resistance to stress, low vigor etc.) in new genotypes produced by genetic improvement. Intra-cultivar diversity was investigated using different molecular approaches and the results showed that the extent of clonal diversity in olive trees seems to be dependent on the cultivar. For example, Galega cv (Gemas et al., 2002) and Biancolilla and Giaraffa cvs (Caruso et al., 2014) are cultivars with evident clonal variation. In contrast, Coratina and Frantoio cvs (Muzzalupo et al., 2010) and Uslu and Ayvalik cvs (Ipek et al., 2012) display less genetic variation.

Leccino, an ancient autochthonous cultivar of Tuscany (Italy), is one of the most important Italian olive cultivars, cultivated in various countries around the world (Bartolini, 2008). The cultivar is self-incompatible (Montemurro et al., 2019) and therefore to obtain a good yield it is necessary to associate the variety with others that are also good pollinizers. It has potentials for growing under different agricultural systems, and produces high quality of extra virgin olive oil. The cultivar also shows a good tolerance to biotic and abiotic stress (Bernardi et al., 2015) and recent observations in the field confirmed a low susceptibility to Xylella fastidiosa (Giampetruzzi et al., 2016). Morphological and/or molecular characterization has been studied to highlight intra-cultivar variability in cultivar (Morettini, 1972; Cantini et al., 1999; Cantini et al., 2008; Muzzalupo et al., 2010), but the results appear to show disparity probably due to the lack of a reference cultivar (Ganino et al., 2006). For this reason, to date the polyclonal origin of this cultivar remains uncertain. To resolve this problem, it was necessary to analyze an ancient population of Leccino widespread in origin zone (Tuscany, IT). The aim of this study was the characterization of Leccino ancient accessions using agromorphological, biochemical and molecular markers.

Results

\section{Evaluation of morphological traits and phenotypic characterization}

Descriptive statistical values (arithmetic means, standard deviation (SD), coefficient of variation (CV), repeatability coefficient ( $R$ ), minimum and maximum) of the examined traits are summarized in Table 1 . The coefficient of variation (CV) varied from $4.04 \%$ to $80.6 \%$, and the traits related with growth and production data (e.g., Cumulate production, CY; Production Efficiency1, CYE; Production Efficiency2, TYE; Cross-sectional area of trunk, AT) showed high values than the morphological traits. Fifteen out of the twenty-five quantitative traits showed a CV of $10 \%$ and of these, four displayed values less than $5 \%$, indicating the least variation among all the accessions for these traits (Table 1). R-value varied from 0.37 for CY trait to 0.88 for Leaf width (LW)
(Table 1). According to Resende (2002), $R$ values greater than 0.6 are considered high, and high values indicate that the trait is expressed with high stability. In our experimental conditions leaf, fruit and pit traits showed $R$ coefficients greater than or equal to 0.6 . The means estimated for each trait, grouped by Tukey test $(p<0.05)$, showed no statistically significant differences among accessions for 10 of morphological quantitative trais. Height traits (Length of one-year-old shoots, Lsh; Fruit length, FrL; Fruit length/width ratio, FrL/FrW; Fruit fresh weight, FrFW; Pit length, PL; Pit fresh weight, PFW; Leaf length/width ratio, LW/LL; and leaf width, LW), instead, showed low or moderate variations among the accessions (Table S1). Furthermore, the qualitative characteristics of fruit, pit and leaf showed identical patterns for all plants in study (Table S2). The observed values in qualitative traits were comparable with those reported in the "World catalogue of olive varieties" (Barranco et al., 2000) and in the OLEA database (Bartolini, 2008) for the Leccino cv. All Leccino accessions shared morphological similarity with Leccino standard (LESt). The Grower binary similarity coefficient and PCA were carried out to identify the relationships between Leccino accessions and between these and Leccino LESt. In general, a high rate of similarity was observed among the evaluated accessions with values ranged between 0.70 and 0.91 , with a mean of 0.80 (Table 2). LE15 accession had the lowest index when compared to other accessions. When the LESt was compared with all accessions, the similarity coefficients showed values equal to or greater than 0.80 (Table 2). When applying PCA to all morphological variables analyzed few strong correlations between traits were highlighted; therefore the compression of information is rather weak, and 8 PCs are necessary to explain more than $90 \%$ of total variance. The first four principal components explain $65 \%$ of the total variance among Leccino accessions (Table S3). The first principal component (PC1) accounted for $27.2 \%$ of the total variance and the traits with the greatest weight on this component were FrL, FrFW and PL. The second component (PC2) explained $16.8 \%$ of the variability, and showed strong negative loads from leaf dimension ( $L L$ and $L L / L W$ ) and from flesh/pit weight ratio (Fl/P) whereas a strong positive load from Intermodal length of one-year-old shoots (ILSh). The most important variables contributing to the third principal component ( $11.8 \%$ of the variability) were leaf fresh weight (LFW) and fruit traits (FrW, FrFW). Finally, Lsh, LL, ILSh showed the higher contribution to fourth principal component (Table S3). The PCA computed for all morphological parameters showed that the points representing different accessions of Leccino are pretty mixed (Fig 1). On the scatter plot, the individuals do not form groups with a wide dispersion among the accessions, indicating that not all genotypes are differentiated. It is interesting to note that almost all points representing LESt are grouped near the center of the mode and LESt presents "average" traits, as compared to the other plants.

\section{Electrophoretic analysis of seed proteins in denaturing conditions}

SDS-PAGE was used to identify variants of protein components in olive seeds. Electrophoretic patterns of seed storage proteins detected the presence of the globulin polypeptides and no differences were detected among the 15 accessions and LESt (a sample is reported in Fig S1A). Electrophoretic patterns in denaturing conditions of the seed teguments protein from the Leccino accessions 
showed height polypeptide bands with molecular sizes ranging from 25.0 to 69.0 kiloDaltons (kDa) (Fig S1B). These bands varied quantitatively and qualitatively with respect to molecular weight. The overall pattern of seed tegument proteins showed that Leccino accessions displayed similar banding pattern but have two distinct peptides ( $51.8 \mathrm{kDa}$ to $33.0 \mathrm{kDa}$ ). Considering the differences in the protein patterns, as reported in diagram (Fig 2) three groups can be distinguished: Group I exhibiting the maximum number of bands and including LESt and 10 Leccino accessions (LE1, LE3, LE5, LE6, LE7, LE11, LE12, LE13, LE14, and LE15); Group II lacking the $51.8 \mathrm{kDa}$ band and composed of the LE4 and LE9; Group III lacking bands 51.8 and $33.0 \mathrm{kDa}$ and including accessions LE2, LE8, and LE10. The similarity index coefficients (SI), valuated between the groups, ranged from 86 to $100 \%$ with an average higher than $90 \%$. Ten accessions showed a value of $100 \%$ similarity with LESt, these accessions representing identical patterns; this means that from this point of identity, such plants were the same and could be considered "Leccino true-to-type", while the others could be considered "Leccino like-to-type".

\section{Genotypic characterization by DNA molecular markers}

In this study, we have considered 30 random oligonucleotide decamer primers for Random Amplified Polymorphic DNA (RAPDs) and 8 oligonucleotide primers for Simple Sequence Repeat (SSRs). RAPD and SSR analysis showed total identity among the Leccino accessions as well as between them and Leccino standard (LESt). In particular, the 30 RAPD primers produced a total of 140 fragments. The fragment sizes of different bands recorded for all samples ranged from 112 to 2500 base pairs (bp) and the number of amplified fragments ranged from 1 (AH30 and 1283) to 9 (1281), with an average of 5.4. Representative profiles of Leccino olives for different primers (1281, OPA03, OPA07, OPA09, OPP15) are depicted in Fig S2. The eight SSR markers produced polymorphic and reproducible amplification fragments, thus identifying 16 alleles. All accessions, including positive control for cultivar identification (LESt), show SSR monomorphic patterns at all the loci tested. The genetic profiles obtained for Leccino accessions resulted identical to the profile of Leccino (CS) cultivar present in the Database of Parma University (Beghè et al., 2011) as further control. The allele sizes are reported in Table 3.

\section{Discussions}

Morphological and agronomic traits are most well-known as the oldest descriptors for identification of olive cultivars. However, phenotyping trees requires a large set of data, the descriptors must be objective and not biased by the environment and require constant phenotypic expression. Additionally, in the case of many woody species, a number of years must pass before the cultivar can be fully described (up to 3-4 years in the case of olive) (Barranco et al., 2000). For these reasons, in this study, the morphological data have been collected on the plants under the same environmental condition and for seven consecutive years. The coefficient of variation (CV) expresses the total variability present in a trait. The distribution of the CV values is classified as low (< $10 \%)$, moderate (10-20\%), high and very high (> 20\%) (Mora and Arriagada, 2016). From a general point of view, the traits with the lowest coefficient (values of $12 \%$ or lower) are suitable in plant characterization (Andrés-Agustìn et al.,
2006). The results obtained showed that 15 morphological traits had values equal to or lower than $10 \%$; these traits were homogeneous and repeatable among Leccino accessions. The repeatability coefficient $(R)$ is the expression of the proportion of total variance of single measurement. $R$ coefficient is defined by differences, both genetically and environmentally controlled among individuals, and it measures the ability of organisms to repeat the expression of a trait over several periods or space (Benin et al., 2005). The $R$ values greater than 0.6 are considered as high. The high values indicate that the trait is expressed with high stability (Resende, 2002). According to Ortiz and Sevilla (1997), for classification and characterization should be used traits with high $\mathrm{R}$ and low CV should be used. The quantitative morphological traits under analysis in our study, expressed as numerical variables, showed these trends, confirming the importance of the traits of leaf, fruit and seed, for the identification of olive cultivars. Although the differences of morphometric traits are often observed in genotypes of the same cultivar (Caruso et al., 2014), the results obtained highlighted that Leccino accessions were characterized by minimum morphological diversity. A group of 10 quantitative variables and 19 qualitative variables did not vary among accessions. The differences for eight variables (LSh, LW, LL/LW, FrL, FrL/FrW, FrFW, PL, and PFW) were small and probably, irrelevant to differentiate the accessions. Moreover, the very low degree of morphological diversity has been detected by high similarity coefficient value (> $80 \%$ ) according to the results of Cantini et al. (1999). The authors highlighted minimal or no morphological differences in Leccino plants collected in different locations in Tuscany and placed in olive germplasm collection. In general, quantitative and qualitative morphological data identified in our Leccino samples, with reduced variability, may represent a reference model for the characterization of the cultivar and for the definition of a "standard reference" as previously asserted by several authors (Caruso et al., 2014; D'Imperio et al., 2011). Biochemical (seed storage proteins and tegument proteins) and molecular markers (RAPD and SSR) were used to assess intra-varietal variability. The electrophoretic patterns of seed proteins have been used by several authors to examine plant variability and to identify species and varieties (Florina, 2012; Drzewiecki et al., 2016). The different tissues of seeds (cotyledon, embryonic axis and tegument) are characterized by different protein contents and profiles (Sghaier-Hammami et al., 2016). The cotyledon presented the highest number of storage proteins (mainly globulins) and the variability of these components is linked to the fact that they represent a multigenic family. SDS-PAGE patterns of seed storage proteins are highly polymorphic and have been widely used as genetic biomarkers for the characterization of several species (Sadia et al., 2009; Bernardi et al., 2017). Analysis of globulin polypeptides did not show differences among accessions and Leccino standard (LESt), while the electrophoretic profile of the tegument total proteins exhibited presence versus absence type of bands. The differences in the seed tegument patterns could be the result of somatic mutations in DNA coding sequences, which may lead to a change within the amino acid sequence of proteins, or to epigenetic changes, or to post-translational modifications induced by specific factors (e.g. orchard management and micro-environmental influences) (Galani et al., 2011; Liu et al., 2015). 
Table 1. Descriptive statistical data (mean, minimum, maximum, SD) Coefficient of Variation (CV) and Repeatability Coefficients (R) of morpho-agronomical traits analyzed. Traits code according to Table S4.

\begin{tabular}{|c|c|c|c|c|c|c|}
\hline Traits & Mean & Minimum & Maximum & SD & CV \% & $\mathrm{R}$ \\
\hline $\mathrm{PH}(\mathrm{m})$ & 3.95 & 2.1 & 5.28 & 0.70 & 27.6 & 0.51 \\
\hline $\mathrm{CP}\left(\mathrm{m}^{2}\right)$ & 5.49 & 1.4 & 11.9 & 2.16 & 39.4 & 0.40 \\
\hline AT $\left(\mathrm{cm}^{2}\right)$ & 93.9 & 7.58 & 229.3 & 51.2 & 54.5 & 0.41 \\
\hline LSh (cm) & 23.5 & 19.2 & 27.6 & 1.72 & 7.33 & 0.81 \\
\hline NNSh (n.) & 10.4 & 8.36 & 13.0 & 0.83 & 7.96 & 0.76 \\
\hline ILSh (cm) & 2.26 & 1.04 & 3.12 & 0.26 & 10.2 & 0.41 \\
\hline $\mathrm{FrL}(\mathrm{cm})$ & 1.94 & 1.45 & 2.27 & 0.15 & 7.96 & 0.77 \\
\hline $\mathrm{FrW}(\mathrm{cm})$ & 1.43 & 1.22 & 1.67 & 0.09 & 6.64 & 0.63 \\
\hline FrL/FrW & 1.36 & 1.13 & 1.61 & 0.07 & 5.36 & 0.72 \\
\hline FrFW (g) & 2.39 & 1.89 & 3.07 & 0.45 & 18.9 & 0.82 \\
\hline $\mathrm{PL}(\mathrm{cm})$ & 1.42 & 1.11 & 1.71 & 0.13 & 9.05 & 0.81 \\
\hline $\mathrm{PW}(\mathrm{cm})$ & 0.69 & 0.61 & 0.79 & 0.03 & 4.45 & 0.80 \\
\hline PL/PW & 2.04 & 1.61 & 2.55 & 0.15 & 7.34 & 0.70 \\
\hline PFW(g) & 0.42 & 0.27 & 0.75 & 0.08 & 18.4 & 0.82 \\
\hline NG (n.) & 10.0 & 9.0 & 11.0 & 0.66 & 6.64 & 0.84 \\
\hline $\mathrm{Fl} / \mathrm{P}$ ratio & 5.72 & 3.07 & 7.59 & 1.03 & 18.2 & 0.60 \\
\hline $\mathrm{LL}(\mathrm{cm})$ & 5.44 & 4.75 & 6.17 & 0.22 & 4.04 & 0.65 \\
\hline $\mathrm{LW}(\mathrm{cm})$ & 1.46 & 1.27 & 1.78 & 0.07 & 4.52 & 0.88 \\
\hline LL/LW & 3.72 & 3.07 & 4.13 & 0.18 & 4.69 & 0.83 \\
\hline $\mathrm{LA}\left(\mathrm{cm}^{2}\right)$ & 6.25 & 5.11 & 7.55 & 0.41 & 6.60 & 0.75 \\
\hline LFW (g) & 0.20 & 0.11 & 0.42 & 0.03 & 10.0 & 0.48 \\
\hline $\mathrm{FrY}(\mathrm{Kg})$ & 7.26 & 1.12 & 15.1 & 3.23 & 43.0 & 0.38 \\
\hline $\mathrm{CY}(\mathrm{Kg})$ & 24.6 & 2.12 & 46.8 & 11.1 & 80.6 & 0.37 \\
\hline CYE $\left(\mathrm{Kg} / \mathrm{cm}^{2}\right)$ & 2.49 & 0.10 & 7.86 & 1.82 & 64.6 & 0.43 \\
\hline TYE $\left(\mathrm{Kg} / \mathrm{cm}^{2}\right)$ & 0.14 & 0.005 & 0.322 & 0.08 & 46.3 & 0.59 \\
\hline
\end{tabular}

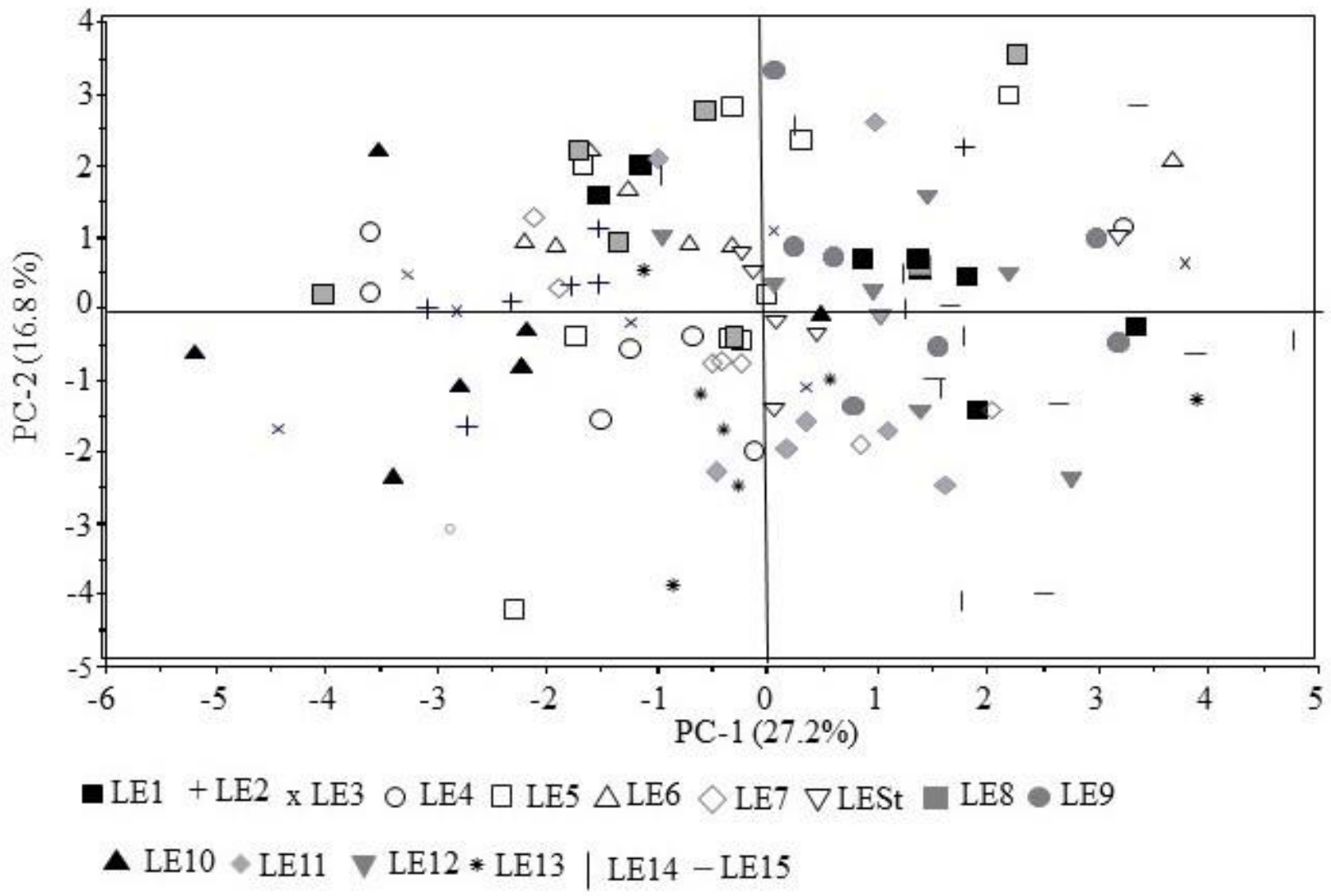

Fig 1. PCA score plot based on morphological data of Leccino accessions with each symbol representing a different accessions. The plot clearly shows that no accession stands out from the bulk of other accessions. 


\begin{tabular}{|c|c|c|c|c|c|c|c|c|c|c|c|c|c|c|c|c|}
\hline LE2 & & 1 & 0.81 & 0.83 & 0.84 & 0.87 & 0.75 & 0.80 & 0.89 & 0.73 & 0.82 & 0.71 & 0.76 & 0.78 & 0.85 & 0.75 \\
\hline LE3 & & & 1 & 0.89 & 0.84 & 0.88 & 0.86 & 0.83 & 0.83 & 0.80 & 0.84 & 0.82 & 0.81 & 0.78 & 0.81 & 0.76 \\
\hline LE5 & & & & & 1 & 0.90 & 0.90 & 0.85 & 0.80 & 0.85 & 0.75 & 0.85 & 0.84 & 0.78 & 0.82 & 0.70 \\
\hline LE6 & & & & & & 1 & 0.82 & 0.81 & 0.84 & 0.83 & 0.74 & 0.81 & 0.78 & 0.77 & 0.81 & 0.74 \\
\hline LE7 & & & & & & & 1 & 0.88 & 0.74 & 0.83 & 0.79 & 0.85 & 0.86 & 0.87 & 0.79 & 0.70 \\
\hline LESt & & & & & & & & 1 & 0.85 & 0.86 & 0.82 & 0.80 & 0.85 & 0.88 & 0.82 & 0.80 \\
\hline LE10 & & & & & & & & & & & 1 & 0.74 & 0.72 & 0.77 & 0.80 & 0.72 \\
\hline Le11 & & & & & & & & & & & & 1 & 0.89 & 0.79 & 0.87 & 0.70 \\
\hline Le12 & & & & & & & & & & & & & 1 & 0.82 & 0.91 & 0.74 \\
\hline LE13 & & & & & & & & & & & & & & 1 & 0.80 & 0.72 \\
\hline LE14 & & & & & & & & & & & & & & & 1 & 0.75 \\
\hline LE15 & & & & & & & & & & & & & & & & 1 \\
\hline
\end{tabular}

\begin{tabular}{|c|c|c|c|c|c|c|c|c|c|c|c|c|c|c|c|c|c|}
\hline \multirow[b]{2}{*}{ Band } & \multirow[b]{2}{*}{ kDa } & \multirow[b]{2}{*}{1} & \multirow[b]{2}{*}{2} & \multirow[b]{2}{*}{3} & \multirow[b]{2}{*}{4} & \multirow[b]{2}{*}{5} & \multirow[b]{2}{*}{6} & \multicolumn{4}{|c|}{ Accessions } & \multirow[b]{2}{*}{11} & \multirow[b]{2}{*}{12} & \multirow[b]{2}{*}{13} & \multirow[b]{2}{*}{14} & \multirow[b]{2}{*}{15} & \multirow[b]{2}{*}{ LESt } \\
\hline & & & & & & & & 7 & 8 & 9 & 10 & & & & & & \\
\hline 1 & 69.0 & - & - & - & - & - & - & - & - & - & - & - & - & - & - & - & - \\
\hline 2 & 56.5 & - & - & - & - & - & - & - & - & - & - & - & - & - & - & - & - \\
\hline 3 & 51.8 & - & & - & & - & - & - & & & & - & - & - & - & - & - \\
\hline 4 & 45.0 & - & - & - & - & - & - & - & - & - & - & - & - & - & - & - & - \\
\hline 5 & 34.0 & - & - & - & - & - & - & - & - & - & - & - & - & - & - & - & - \\
\hline 6 & 33.0 & - & & - & - & - & - & - & & - & & - & - & - & - & - & - \\
\hline 7 & 31.0 & - & - & - & - & - & - & - & - & - & - & - & - & - & - & - & - \\
\hline 8 & 25.0 & - & - & - & - & - & - & - & - & - & - & - & - & - & - & - & 一 \\
\hline
\end{tabular}

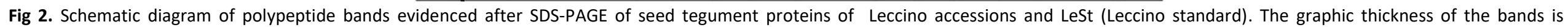

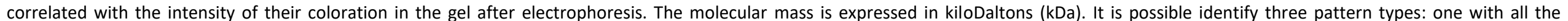

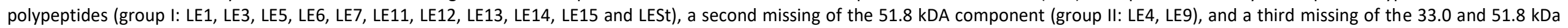
components (group III: LE2, LE8, LE10). 
Table 3. Allele sizes (bp) at 8 SSR loci from 15 Leccino accessions and Leccino standard (LSt). Genetic profile of cultivar LECS of Parma database was inserted.

\begin{tabular}{|c|c|c|c|c|c|c|c|c|}
\hline Code accession & Loci & & & & & & & \\
\hline & DCA3 & DCA5 & DCA9 & DCA16 & DCA18 & GAPU101 & GAPU103 & EMO90 \\
\hline LE 1-LE15 & $243 / 253$ & $199 / 207$ & $163 / 207$ & $151 / 176$ & $177 / 177$ & $200 / 202$ & $176 / 189$ & $187 / 193$ \\
\hline LESt & $243 / 253$ & $199 / 207$ & $163 / 207$ & $151 / 176$ & $177 / 177$ & $200 / 202$ & $176 / 189$ & $187 / 193$ \\
\hline LECS & $243 / 253$ & $199 / 207$ & $163 / 207$ & $151 / 176$ & $177 / 177$ & $200 / 202$ & $176 / 189$ & $187 / 193$ \\
\hline
\end{tabular}

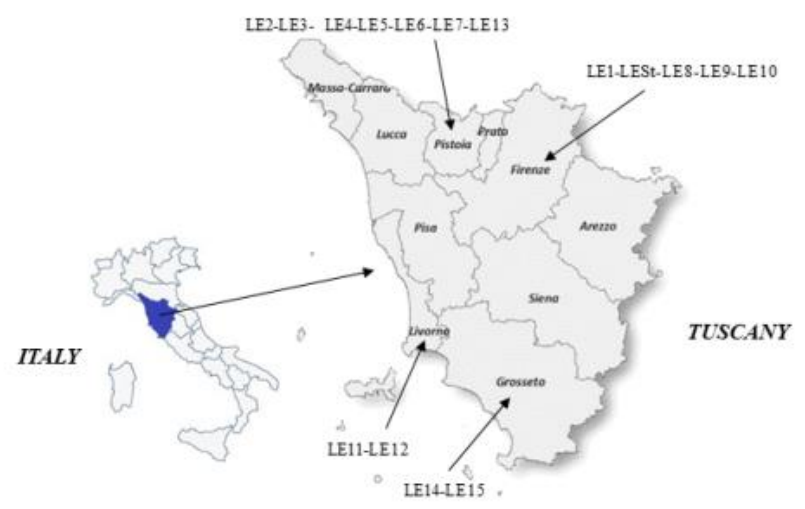

Fig 3. Map of Tuscany region in Italy indicating the collection localities (arrows) of Leccino samples in each Province. The geographic

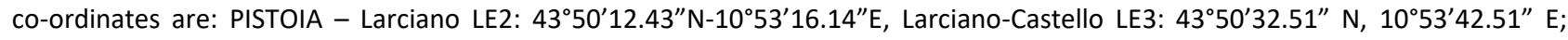
Lamporecchio LE4: $43^{\circ} 49^{\prime} 15.13^{\prime \prime} \mathrm{N}-10^{\circ} 54^{\prime} 44.59^{\prime \prime} \mathrm{E}$, Lamporecchio LE5: 4349'11.27"N, $10^{\circ} 54^{\prime} 58.12^{\prime \prime} \mathrm{E}$; Pescia-S. Lorenzo LE6:

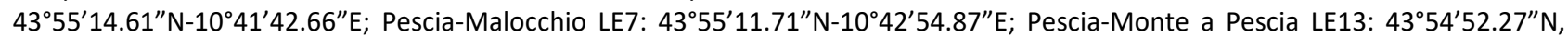

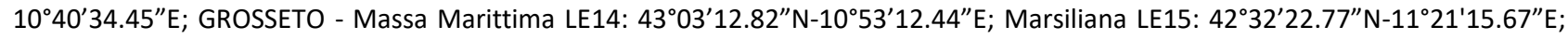

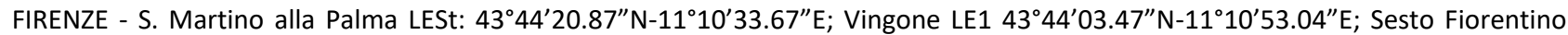

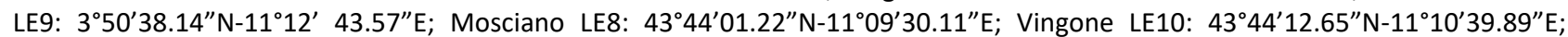

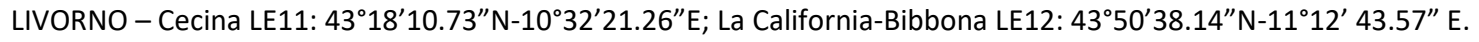

The combined use of RAPD and SSR markers facilitates a high level of genomic coverage, since RAPD markers may be associated with functionally important loci (Arif et al., 2009) and SSR markers amplify the hypervariable non-coding regions (Powell et al., 1996). The results showed SSR monomorphic patterns at all the loci examined for all Leccino accessions and reference cultivar. No differences were detected, also, in RAPD patterns. Although SSRs have a higher capacity to reveal polymorphism and discriminate between genotypes than RAPDs (Belaj et al., 2003), our results clearly demonstrated that the accessions had a unique 'DNA fingerprint' both for RAPD and SSR, confirming homogeneity between Leccino genotypes. The genetic identity of Leccino olive trees detected in this study is in accordance with previous reports (Cantini et al., 2008; Beghè et al., 2011). SSRs markers did not identify genetic intracultivar diversity in Leccino accessions from a CNR collection (Follonica, Italy) (Cantini et al., 2008); similarly, Beghè et al. (2011) detected a dissimilarity less to $2 \%$ in a group of Leccino accessions studied in the Emilia Romagna region.

\section{Materials and methods}

\section{Plant material}

Plant material consisted of 15 ancient olive trees (approximately of one century) cultivar Leccino, collected from private farms, located in several Tuscany provinces (Fig
3). Each accession (mother plant) was clonally propagated. Seven plants (of 2 years), of each accession, were established in a private field collection, Azienda "Poggio Arioso" $\left(42^{\circ} 55^{\prime} 38^{\prime \prime} \mathrm{N}, 10^{\circ} 45^{\prime} 45^{\prime \prime} \mathrm{E}, 66 \mathrm{~m}\right.$ asl) at Scandicci (Florence, Tuscany, Italy). The soil in the zone is clay with a $\mathrm{pH}$ of 7.9, and the climate is transitional Mediterranean, with relatively mild winters and hot, sunny summers. The plants were placed at a distance of $6.0 \mathrm{~m} \times 6.0 \mathrm{~m}$, using a completely randomized design. All the recommended treatments (production systems, conditions and pruning) for olive tree were applied. Trees of the cv Leccino recorded by the Tuscan Region (reference mother plant for the varietal correspondence) were grown in the same field and used as reference. The accessions were tagged with an identification code (LE1-LE15) and Leccino tree, descripted by Tuscany Region Council, was categorized as Leccino standard (LESt).

\section{Leccino trees characterization and identification of morpho-} agronomic traits

Accessions (LE1-LE15) and LESt were examined for 44 phenotypic traits resulting in 25 quantitative (morphological and agronomic traits) and 19 qualitative descriptors related to the characteristics of the plants, leaves, fruits and pit (Table S4). The trait selection was carried out by using the methodology proposed by Barranco et al. (2000) and OLEA databases (Bartolini 2008). All traits were detected, from the third year of planting, on clonally propagated plants and during 7-years (2007-2013) period. The PH (m) was 
measured from the soil level to highest point, the CP $\left(\mathrm{m}^{2}\right)$ was calculated as a circular projection of the canopy to the soil, and the AT $\left(\mathrm{cm}^{2}\right)$ was calculated using the measurement of trunk circumference at $\sim 15 \mathrm{~cm}$ above the soil. Circumference was measured at a marked point on the trunk, and converted to AT by the relation of circumference equal to $2 \pi r$, the radius was calculated and with the relation of area equal to $\pi r^{2}$, cross-sectional area was measured.

At harvest time, fruit yield per tree (FrY; $\mathrm{Kg}$ ) and the Cumulate production ( $\mathrm{CY} ; \mathrm{Kg}$ ), as sum of annual production for the seven years of observations, were determined. The Yield Efficiency1 (CYE, $\mathrm{Kg} / \mathrm{cm}^{2}$ ) was calculated as projected crown/plant production, and Yield Efficiency2 (TYE, $\mathrm{Kg} / \mathrm{cm}^{2}$ ) was considered as basal trunk sectional area/plant production.

One-year shoots were collected from fruiting branches to approximately 1-1.5 $\mathrm{m}$ above the ground in different parts of the canopy, and length (LSh; $\mathrm{cm}$ ) and node numbers (NNSh; n.) determined. Leaf traits were evaluated on fifteen mature leaves collected randomly from the medial part of 1-year-old branches. Fruit and pit traits were measured from fifteen fruit harvested randomly at maturity (October). The fruits were taken in the intermediate zone of the south-facing branches, and the extreme values were eliminated. The qualitative traits of leaf, fruit and pit are reported in Table S4. All variables, both the quantitative and the qualitative, expressed as variables in numerical scale (e.g., length and width), in ordinal scale (e.g., low-medium-high) and in nominal scale (e.g., presence-absence, color, shape, etc.) were analyzed. The data of mean values obtained from seven plants in the seven years, were used for statistical analysis.

\section{Protein extraction and SDS-PAGE analysis}

Leccino accessions and LESt were subjected to protein profiling, using gel electrophoresis in denaturing conditions (SDS-PAGE). For SDS-PAGE analysis, two protein groups of mature seeds were investigated: the storage proteins and the tegument proteins. Extraction and electrophoresis of seed storage proteins were carried out according to Bernardi et al. (2017). For the analysis of the tegument proteins, the seed coat $(0.1 \mathrm{~g})$ was separated from the embryo, ground in liquid nitrogen and $5 \%(w / w)$ of Polyvinylpyrrolidone (PVP) was added. Total proteins were extracted at $4^{\circ} \mathrm{C}$, in $400 \mu \mathrm{l}$ of $25 \mathrm{mM}$ Tris-phosphate buffer $(\mathrm{pH} 7.0)$ containing $0.4 \% \beta$ mercaptoethanol. The homogenate was centrifuged (12000 $\mathrm{x} g$ for $15 \mathrm{~min}$ ) and the clear supernatant was assayed for protein content (BioRad protein assay kit II BioRad, Laboratories $\mathrm{GmbH}$, Muenchen, Germany). SDS-PAGE was carried out according to Bernardi et al. (2017). Densitometry readings were performed by direct scanning of the stained gel with Quantity one Software (BioRad, USA). Molecular weight standards (M.W. expressed in $\mathrm{KDa}$ ) were used as markers (Low Range Bio-Rad, Hercules, CA, USA). In order to augment accuracy, all experiments including exaction and SDS-PAGE were repeated at least three times.

\section{DNA extraction and RAPDs and SSRs analysis}

Leccino accessions and LESt were subjected to genome fingerprinting, using RAPD-PCR and SSR analysis. The molecular markers used were: for RAPD technology, OPA 01,
02, 03, 05, 07, 09, 11, OPA4, OPA U, OPP 02, 06, 10, 12, 13, 14, 15 and 18, $\mathrm{AH} 10,11,16,17,18,29$, and 30, (Operon Technologies Alameda, CA, USA), CD 12, 1281, 1283, AI 2, CD 11, AG 1 (Genenco, Florence, Italy; Bogani et al., 1994); for SSR analysis, ssrOeUA-DCA-(03, 05, 09, 16, 18) (Sefc et al., 2000), ssrOe-GAPU-(101, 103A) (Carriero et al., 2002) and EMO90 (de la Rosa et al., 2002). The SSR primers were preselected for high discriminative power, high polymorphism and easily scorable patterns by Baldoni et al. (2009). Total genomic DNA was extracted from young leaves using the CTAB procedure (Doyle and Doyle, 1987). The concentration and purity of DNA were assessed spectrophotometrically (ND-100 spectrophotometer, NanoDrop Technologies Wilmington, DE, USA) and visualized on $0.8 \%$ agarose gel. RAPD and SSR analysis were performed following the protocol of Bogani et al. (1994) and Ganino et al. (2008) respectively, using a Perkin-Elmer 9600 (USA) termocycler. The RAPD profiles obtained with each utilized primer were analyzed by comparison with DNA molecular marker VI (Boehringer, Mannehim, Germany). Amplification patterns evaluated with the Kodak digital sciences 1 D Images Analysis Software, calculating the size in base pairs (bp) of each band present. For SSR analysis, the amplification products were separated with a CEQ 2000 Genetic Analysis System (Beckman Coulter, Inc.) sequencer on acrylamide gel CEQ Separation Gel LPA-1 (Beckman Coulter, Inc.). A marker CEQ DNA Size Standard kit 400 (Beckman Coulter, Inc.) was used to estimate the approximate molecular weight of the amplified products. One of the two PCR primers in each reaction was end-labeled with a fluorescent dye (Cy5 and IRD 700, MWG-Biotech, Ebersberg).

\section{Statistical analysis}

ANOVA analysis was performed first for the phenotypic data, simple univariate statistics including means, range, standard deviation (SD) and coefficient of variation (CV) calculated as indicator of variability. The coefficient of repeatability (R) of each trait, was computed as $R=S_{A}^{2} /\left(S_{A}^{2}+S_{W}^{2}\right)$, where $S_{A}^{2}$ is the variance among groups and $S_{W}^{2}$ is the variance within groups (Wolak et al., 2012).

The significance of differences between accessions and between these and the Leccino standard was assessed by one-way analysis of variance (ANOVA) of morphological traits, using the Tukey's test honestly significant difference (HSD). Significant differences between accessions were determined at the 95\% confidence level $(p \leq 0.05)$. The Similarity Coefficients (CS) and Principal Component Analysis (PCA-analysis) were applied to gauge the relationship between Leccino plants. CS was calculated considering the formula for a quantitative variable $S_{i j k}=1-\left|x_{i k}-x_{j k}\right| / R_{k}$, where $x_{i k}$ and $x_{j k}$ are the values of variable $k$ for individuals $i$ and $j$, respectively, and $R_{k}$ is the range of variable $k$ in the sample (Gower, 1971). The PCA analysis was performed using the NIPALS algorithm and the Unscrambler $X^{\circledR}$ software (Camo, Oslo, Norway).

For SDS-PAGE the data were scored as (1) for the presence and $(0)$ for the absence of a given band and the similarity among Leccino accessions was determined by $S I$ (similarity Index; Nei and Li, 1979): $S I=2 N_{x y} /\left(N_{x}+N_{y}\right) . N_{x y}$ is the number of protein bands shared between the individuals $x$ and $y$, and $N_{x}$ and $N_{y}$ are the number of bands in individual $x$ and $y$, respectively. Data from RAPD patterns were treated 
as binary traits (present $=1$ or absent $=0$ ). For SSR analysis, the fragments were sized by using a conservative binning approach (Kirby, 1990) through the statistical R software (R Development Core Team, 2005), which takes into account the type of replicate and compensates for the limits of fragment resolution. The SSR profiles obtained by the genotype analysis of accessions and LESt were compared with the genotype profile of a cultivar Leccino-Cosenza, (Leccino CS) (from the collection of the CRA Research Centre for the Olive Growing and Olive Oil Industry of Rende (Cosenza, Italy)), present in the Database of Parma University (Beghè et al., 2011 and data unpublished), as further control.

\section{Conclusion}

In this paper are presented the results obtained by analyzing morphological and genetic markers in several samples of the Leccino cultivar of Olea europaea coming from different locations in the Tuscany region (Italy). On the base of the experimental data, the Leccino cultivar seem to be an ancient monoclonal Tuscany olive variety. This hypothesis is confirmed by genetic and morphologic results. A little difference was detected by seed polypeptides analysis, and this difference could be due to spontaneous or induced mutations.

\section{References}

Andrés-Agustín J, González-Andrés F, Nieto-Ángel R, Barrientos-Priego AF (2006) Morphometry of the organs of cherimoya (Annona cherimola Mill.) and analysis of fruit parameters for the characterization of cultivars, and Mexican germplasm selections. SciHortic. 107(4):337-346.

Arif M, Zaidi NW, Singh YP, RizwanulHaq QM, Singh US (2009) A comparative analysis of ISSR and RAPD markersfor study of genetic diversity in shisham (Dalbergia sissoo). Plant Mol Biol Rep. 27(4):488-495.

Baldoni L, Cultrera NG, Mariotti R, Ricciolini C, Arcioni S, Vendramin GG, Buonamici A, Porceddu A, Sarri V, Ojeda MA, Trujillo I, Rallo L, Belaj A, Perri E, Salimonti A, Muzzalupo I, Casagrande A, Lain O, Messina R, Testolin R (2009) A consensus list of microsatellite markers for olive genotyping. Mol Breeding. 24(3):213-231.

Bartolini G (2008) Olive germplasm (Olea europaea L.), cultivars, synonyms, cultivation area, collections, descriptors. http://www.oleadb.it/.

Barranco D, Cimato A, Fiorino P, Rallo L, Touzani A, Castañeda C, Serafín F, Trujillo I (2000) World catalogue of olive varieties. International Olive Oil Council, Madrid. 360.

Beghè D, Ferrarini A, Ganino T, Fabbri A (2011) Molecular characterization and identification of a group of local Olea europaea L. varieties. Tree Genet Genomes. 7(6):11851198.

Belaj A, Satovic Z, Cipriani G, Baldoni L, Testolin R, Rallo L, Trujillo I (2003) Comparative study of the discriminating capacity of RAPD, AFLP and SSR markers and their effectiveness in establishing genetic relationships in olive. Theor Appl Genet. 107(4):736-744.

Benin G, Hartwig I, de Carvalho FIF, de Oliveira AC, Vieira EA, Bertan I, da Silva JA, Valério IP, Ribeiro G (2005) Repeatability estimates of genetic, phenotypic and environmental correlations in oats with and without fungicide application. Crop Breed Appl Biot. 5(2):183-190.

Bernardi R, Bartolini G, Petruccelli R, Salvini M, Durante M (2015) Modulated gene expression during the cold acclimation process in tolerant and sensitive clones of cultivar Leccino (Olea europaea L.). Plant Omics. 8(5):405411.

Bernardi R, Petruccelli R, Bartolini G, Durante M (2017) Polymorphisms of seed storage proteins in Olea europaea L. cultivars. Asian Res J Agric. 4(4):1-6.

Bogani P, Cavalieri D, Petruccelli R, Polsinelli L, Roselli G (1994) Identification of olive tree cultivars by using random amplified polymorphic DNA. Acta Hortic. 356:98101.

Cantini C, Cimato A, Autino A, Redi A, Cresti M (2008) Assessment of the Tuscan olive germplasm by microsatellite markers reveals genetic identities and different discrimination capacity among and within cultivars. J Am Soc Hortic Sci. 133(4):598-604.

Cantini C, Cimato A, Sani G (1999) Morphological evaluation of olive germplasm present in Tuscany region. Euphytica. 109(3):173-181.

Carriero F, Fontanazza G, Cellini F, Giorio G (2002) Identification of simple sequence repeats (SSRs) in olive (Olea europaea L.). Theor Appl Genet. 104:(2-3):301-307.

Caruso T, Marra F, Costa F, Campisi G, Macaluso L, Marchese A (2014) Genetic diversity and clonal variation within the main Sicilian olive cultivars based on morphological traits and microsatellite markers. Sci Hortic. 180:130-138.

D'Imperio M, Viscosi V, Scarano MT, D'Andrea M, Zullo BA, Pilla $F$ (2011) Integration between molecular and morphological markers for the exploitation of olive germoplasm (Olea europaea). Sci Hortic. 130(1):229-240.

de la Rosa R, James CM, Tobutt KR (2002) Isolation and characterization of polymorphic microsatellites in olive (Olea europaea L.) and their transferability to other genera in the Oleaceae. Mol Ecol Notes. 2:265-267.

Doyle JJ, Doyle JL (1987) A rapid DNA isolation procedure for small quantities of fresh leaf tissue. Phytochem Bull. 19:11-15.

Drzewiecki J, Latocha $\mathrm{P}$, Leontowicz $\mathrm{H}$, Leontowicz $\mathrm{M}$, Park YS, Najman K, Weisz M, Ezra A, Gorinstein S (2016) Analytical methods applied to characterization of Actinidia arguta, Actinidia deliciosa, and Actinidia eriantha kiwi fruit cultivars. Food Anal Method. 9(5):1353-1366.

Florina F (2012) Assessment of genetic diversity in a collection of local tomatoes by SDS-PAGE method. J Hortic Sci Biotechnol. 16(3):133-136.

Ganino T, Bartolini G, Fabbri A (2006) The classification of olive germplasm-a review. J Hortic Sci Biotech. 81(3):317-334.

Ganino T, Beghè D, Rotondi A, Fabbri A (2008) Genetic resources of Olea europaea $\mathrm{L}$. in the Bologna province (Italy): SSR analysis and identification of local germplasm. Adv Hortic Sci. 22(2):149-155.

Galani S, Naz F, Soomro F, Jamil I, Zia-ul-hassan, Azhar A, Ashraf A (2011) Seed storage protein polymorphism in ten elite rice (Oryza sativa L.) genotypes of Sindh. Afr J Biotechnol. 10(7):1106-1111.

Gemas VJV, Rijo-Johansen MJ, Fevereiro P (2002) Intravariability of the portuguese olive cultivar Galega vulgar expressed by RAPD, ISSR and SPAR. Acta Hortic. 586:175178. 
Giampetruzzi A, Morelli M, Saponari M, Loconsole G, Chiumenti M, Boscia D, Savino VN, Martelli GP, Saldarelli P (2016) Transcriptome profiling of two olive cultivars in response to infection by the CoDiRO strain of Xylellafastidiosa subsp. Pauca. BMC Genomics. 17(1):475.

Gower JC (1971) A general coefficient of similarity and some of its properties. Biometrics. 27(4):857-871.

Ipek A, Barut E, Gulen H, Ipek M (2012) Assessment of interand intra-cultivar variations in olive using SSR markers. Sci Agric. 69(5):327-335.

Kirby LT (1990) Probability and statistical analysis. In: Kirby LT (ed) DNA Fingerprinting. Palgrave Macmillan, London. 149-177.

Liu X, Luo M, Yang S, Wu K (2015) Role of epigenetic modifications in plant responses to environmental stresses. In: Pontes $\mathrm{O}$, Jin $\mathrm{H}$ (eds.) Nuclear functions in plant transcription, signaling and development. Springer Science Business Media, New York. 81-92.

Lopes MS, Mendonca D, Sefc KM, Gil FS, da Camara Machado A (2004) Genetic evidence of intra-cultivar variability within Iberian olive cultivars. HortScience. 39(7):1562-1565.

Montemurro C, Dambruoso G, Bottalico G, Sabetta W (2019) Self-Incompatibility assessment of some Italian olive genotypes (Olea europaea L.) and cross-derived seedling selection by SSR markers on seed endosperms. Front Plant Sci. 10:451.

Mora F,Arriagada O (2016) A classification proposal for coefficients of variation in Eucalyptus experiments involving survival, growth and wood quality variables. Bragantia. 75(3):263-267.

MorettiniA (1972) Olivicoltura. 2rd edn. REDA, Roma. 7.

Muzzalupo I, Chiappetta A, Benicasa C, Perri E (2010) Intracultivar variability of three major olive cultivars grown in different areas of central-southern Italy and studies using microsatellite markers. Sci Hortic. 126(3):324-329.

Nei M, Li WH (1979) Mathematical model for studying genetic variation in terms of restriction endonucleases. $P$ Natl Acad Sci USA. 76(10):5269-5273.
Ortiz R, Sevilla R (1997) Quantitative descriptors for classification and characterization of highland Peruvian maize. Plant Genet Resour Newsl. 110:49-52.

Powell W, Morgante M, Andre C, Hanafey M, Vogel J, Tingey S, Rafalski, A (1996) The comparison of RFLP, RAPD, AFLP and SSR markers for germplasm analysis. Mol Breeding. 2(3):225-238.

Resende MDV (2002) Genética biométrica e estatística no melhoramento de plantasperenes. Embrapa Informação Tecnológica, Brasilia. 975.

Roselli G, Donini B, Petruccioli G (1982) Aspects of olive tree breeding. In: Gupta SK (ed) Improvement of oil-seed and industrial crops by induced mutations. International Atomic Energy Agency, Vienna.119-138.

R Development Core Team (2005) R: a language and environment for statistical computing. $\mathrm{R}$ Foundation for statistical computing. Vienna, Austria. http://www.Rproject.org.

Sadia M, Malik SA, Rabbani MA, Pearce SR (2009) Electrophoretic characterization and the relationship between some Brassica species. eJBio. 5(1):1-4.

Sefc KM, Lopes MS, Mendonça D, Rodrigues Dos Santos M, Laimer Da Câmara Machado M, Da Câmara MA (2000) Identification of microsatellite loci in olive (Olea europaea L.) and their characterization in Italian and Iberian olive trees. Mol Ecol. 9(8):1171-1173.

Sghaier-Hammami B, Redondo-López I, Valero-Galvàn J, Jorrín-Novo JV (2016) Protein profile of cotyledon, tegument, and embryonic axis of mature acorns from a non-orthodox plant species: Quercus ilex. Planta. 243(2):369-396.

Vossen P (2007) Olive oil: history, production, and characteristics of the world's classic oils. HortScience. 42(5):1093-1100.

Wolak ME, Fairbairn DJ, and Paulsen YR (2012) Guidelines for estimating repeatability. Methods EcolEvol. 3(1):129137. 